Asian Journal of Information Technology 11 (1): 7-13, 2012

ISSN: $1682-3915$

(C) Medwell Journals, 2012

\title{
A Framework of a Web-Based Database System for National Health Insurance Scheme
}

\author{
V.V.N. Akwukwuma and C.E. Igodan \\ Department of Computer Science, Faculty of Physical Sciences, \\ University of Benin, P.M.B. 1154 Benin City, Nigeria
}

\begin{abstract}
The advent of the world wide web heralds seamless storage, process, retrieval and dissemination of information the world over. The use of the web technology for Healthcare Information Management System has led to effective healthcare delivery by enabling easy and timely access to patient's information with little or no cost. Presently, the National Health Insurance Scheme does not have a Centralized Patient Information System for the healthcare centres in Nigeria to access patient's information for healthcare delivery. This study proposes a Web-Based Database System of patients' information repository for effective and timely access to information when and where it is needed. The design uses the three-tier web model architecture as its underlying technology and presents an architectural design for a Centralized Information Database System. If the system is deployed, it will save time in accessing patients' health information and hence, prompt healthcare delivery will be achieved and also open a new trend for the health industries. Apache server, PHP, HTML and MySql was used for the design.
\end{abstract}

Key words: Centralized information database system, National health insurance scheme, patient's information repository, patient's healthcare information system, world wide web

\section{INTRODUCTION}

The National Health Insurance Scheme (NHIS) in 2004 got a presidential mandate to ensure a nationwide coverage of the social health system by 2015 (Moses, 2011). Unfortunately, the government is still grappling with the task of achieving their aims and objectives. Moses (2011) opined that $>75 \%$ of the country's population is not included in the National Health Insurance Scheme (NHIS). Although, it would be a welcome development to expand the scheme to accommodate all Nigerian, government however, must address some of the challenges which have to do with capturing an accurate data of the enrollees of the scheme. Today in Nigeria, patients' data kept by the NHIS are scattered among various Health Maintenance Organizations (HMOs). In order for this scattered interrelated data to be properly organized for accessibility, retrieval and distribution among health care practitioners for prompt delivery and effective services, the internet can be used as a tool to solve this problem by capturing these data into a centralized online data repository. In Nigeria, the health sector is principally financed by the government. The government is faced with various challenges such as stagnant mono-cultural economy that depends on crude oil as a single export commodity, a rapid population growth, political instability, high rate of unemployment and terrorism. Hence, the government cannot afford to commit enough money to the health sector which is now faced with the consequence of underfunding-decreased efficiency, poor quality/quantity of service, diminishing confidence in public sector health facilities and poor maintenance culture. According to Adesina (2009) health insurance is a means of spreading the risks of incurring health care cost over a group of individuals and households. Healthcare costs are often unaffordable to individuals if they have to pay the full cost of treatment as it occurs. Health Insurance is defined as the ability to get health services when required without having to pay fully at the time of need because payment has been made by a fixed regular contribution by the insured or his/her employer or both (prepayment plan). Adesina (2009) opined that health insurance is the pooling of resources by groups of individuals to take care of such needs. It entails risk sharing by contributors thus individuals with higher resources subsidise those with less and those with low incidence of illness subsidise those who require care more frequently. The money is pooled by the provider of the insurance to pay for all those needing health care. Health insurance is now

Corresponding Author: V.V.N. Akwukwuma, Department of Computer Science, Faculty of Physical Sciences, University of Benin, P.M.B. 1154, Benin City, Nigeria 
regarded as probably the most common form of financing healthcare worldwide. However, the government introduced the National Health Insurance Scheme so that the low income earners can access health care services at a reasonable low price. This has helped to improve the distribution of health care services in recent times.

The information gathering system in the NHIS is one major problem that reflects on how care givers response to emergencies, treatment and services in the health system. According to Chiemeke et al. (2004) information system is a set of hardware, software, data, people and procedures that work together to produce information. The healthcare environment is generally perceived as being information rich yet knowledge poor (Kaur and Wasan, 2006). Unfortunately, the information gathering of the NHIS is still not fully achieved and utilized to improve the quality of services. This study proposes a framework of a web based database system for the management of patients' information which is design around the functionalities of the National Health Insurance Scheme (NHIS) in Nigeria for the delivery of health care services.

The objectives of the NHIS: The following are the objectives of the National Health Insurance Scheme:

- To ensure that every Nigerian has access to good health care services

- To solve the problem of inappropriate use of levels of health care, leading to unnecessary cost and underutilization of specialized facilities ensuring equitable patronage of all levels of health care

- To improve and harness private sector participation in health care service delivery and to ensure institutional quality assurance

- Protect families from the financial hardship of huge medical bills

- To ensure equitable distribution of healthcare cost among different income groups

- Limiting the rise in the cost of healthcare service

- To maintain high standard of healthcare delivery services within the scheme

- To ensure availability of funds to the health sector for improved services and foster research in the health sector

- To ensure efficiency in healthcare services

- To ensure adequate distribution of health facilities within the federation

In Nigeria today, there are still challenging factors that are militating against the health care industry in meeting the scheme's objectives. These factors are obviously the non-availability of knowledgeable medical practitioners having computer skills evenly distributed in the six geopolitical area of the country, the epileptic power supply over the past two decades, bad road networks insensitivity of the government to revamp the health sector over the years, the non-availability of primary health care services at the grass root to cater for the immediate medical needs of rural areas dwellers and increasing number of people and lack of interest of the private sector to partner with the health organization because of the non availability of security and conducive and healthy environment for participation.

Types of health insurance scheme: According to Adesina (2009), there are three types of health insurance scheme:

Private: This is through employer owned on sight health facilities or through contract with outside providers.

Social: Payment is irrespective of needs and is usually based on employment and income. It is a form of payroll tax sharing between employers and employee earmarked to pay for health care.

Community health insurance: Community based programme which normally operates in the rural areas and mostly localised. It is co-ordinated and organised by cooperative societies, unions and non-governmental organisations.

\section{BACKGROUND ON HEALTHCARE SYSTEMS}

In developing countries like Nigeria, there is little improvement in making hardware and software available for health care services which has also affected the organization of medical data for effective health care delivery. According to Wiederhold et al. (2001) Health care information system is a field of study concerned with the broad range of issues in the management and use of biomedical information including medical computing and the study of the nature of medical information itself. If physiology literally means the study of life and pathology is the logic of disease then health informatics is the logic of healthcare which is the science that studies the use and processing of data information and knowledge applied to medicine, health care and public health (Van Bemmel, 1997). Some of the goals of health care systems as reported in WHO (2000) are good health, responsiveness to the expectations of the population and fair financial contribution which form a major building block for health care delivery system. In evaluating Health Care System. Duckett (2004) proposed a two dimensional approach: quality, efficiency and acceptability on one dimension and 
equity on another. The basics of Health Care System (HCS) remain the same national coverage for medically necessary health care services provided on the basis of need and quality, rather than the ability to pay. About 2 major models have been identified in the design of Health Care Systems: private and public models. Private enterprise health care systems are comparatively rare. Where they exist, it is usually for a comparatively well-off subpopulation in a developing country with a poorer standard of health care. For instance, private clinics are primarily established to take care of the small, wealthy expatriate population in the country. The other major model is the public insurance systems. Instances of these could be social security, publicly funded health care, social health insurance health care model and so on.

This model caters for the people insured by the government (Piattini and Diaz, 2000). The basic areas of a successful health care industry are Funding, e-Health, Home and Continuing Care, Health Care Delivery System, Hospital Care, Nursing Policy, Palliative and End of life Health care, Pharmaceuticals, Primary Health Care, Legislation and Guidelines, Report and Publication and Health Services just to mention a few. While the strength of these areas is not evident in the present Nigeria Health Care System, it is worthy to note that the present government is doing everything humanly possible to improve the Health Care System of the nation (Obembe and Ogundele, 2009). This study discusses the distribution of the inter-related information handled by the National Health Insurance Scheme for easy access of patient's data by healthcare professionals for service delivery. It focuses on the issues affecting the availability of patient's information at the point of care in facilitating access to health care promptly and above all, it provides a platform for data gathering and sharing among health care providers and government for effective and proper planning by the government for proper distribution of the benefits of the scheme across the country.

\section{INFORMATION DATABANK FOR NHIS}

Accurate, relevant and accessible information is achieved through a modern and effective Health Information System (HIS). In improving the performance of the health system and improving the health of patients, timely information access is vital. The internet in the world over has bridged the gap in the information world. Its use helps to make information communication seamless and effective which breaks the barrier of lack of information among the key players in the health care industry and enabling the scheme in meeting and achieving results

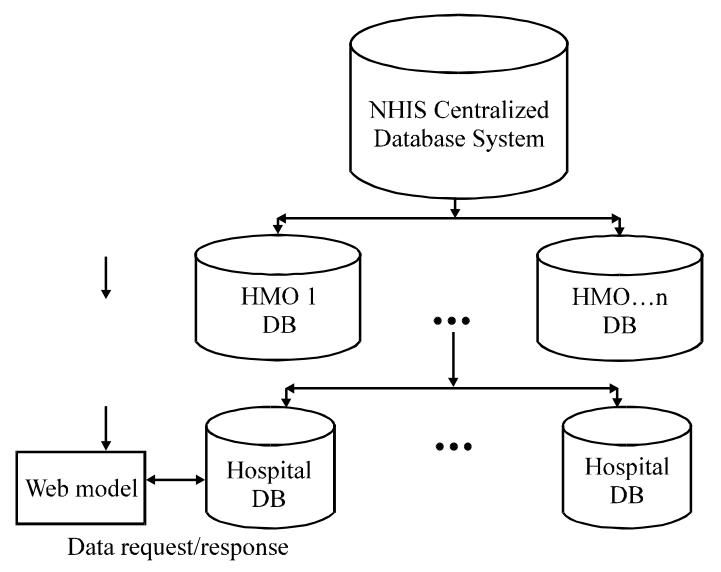

Fig. 1: Schematic representation of the proposed system

in delivering services to the people. This system will allow the development of a database system where available health care services are made known to the public through a web front. The schematic representation of the proposed system is shown in Fig. 1.

The Fig. 1 shows a brief relationship between the unified data repository containing details of the NHIS, $\mathrm{HMOs}$, care providers (primary and secondary) and the general public who also can access information with restriction. The data is provided by the clients through their primary and secondary care providers, respectively. The health administrators are in control of the health information system at the NHIS central database using the web services technology which is discussed at the latter part of this study.

\section{THE WEB DATABASE SYSTEMS}

The development and deployment of a web based system is driven by the three-tier application using database on the internet. The architecture of the three-tier is shown in Fig. 2. The three-tier architecture is described:

Front-tier: A front-end web server serves static content and potentially some cached dynamic content. In web based application, front end is the content rendered by the browser. The content may be static or generated dynamically.

Middle-tier: A middle dynamic content processing and generation level application server for example, Ruby on Rails, Java EE, ASP.NET, PHP and ColdFusion platform.

Back-tier: A back-end database comprises both data sets and the Database Management System or RDBMS Software that manages and provides access to the data. 


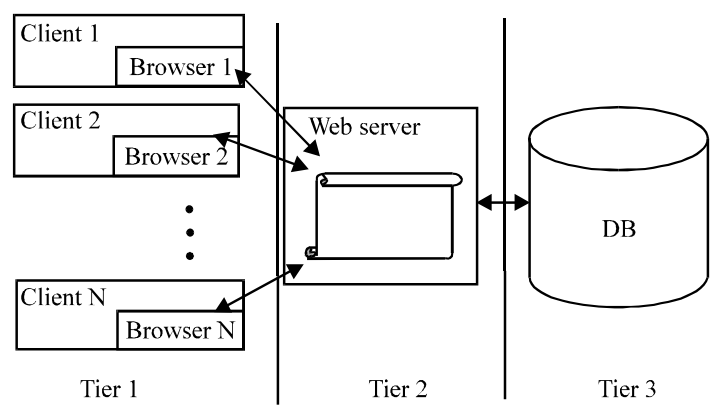

Fig. 2: Three Tier Web Model (Obembe and Ogundele 2009)

\section{ANALYSIS OF THE EXISTING SYSTEMS}

The present mode of registration of prospective members into the NHIS in Nigeria is manually done and quite a tasking one. To register in the scheme, one has to present his/her letter of employment and thereafter given a data caption form capturing the vital details about the person. The liaison officer-a staff of the HMO (premier medicaid) resident in the healthcare centre collects the form and generates a temporary ID card which is used to access healthcare temporarily until either minimum of 3 or maximum of 6 months before a permanent ID card is issued. Most times it takes 1 or 2 years to get an ID card. A case note is opened to record patient's history. If a person is married, he/she can register his/her spouse and maximum of 4 children $<18$ years of age to enjoy the scheme. But if a person is not married at the time of fist registration and latter got married, he/she would have to pay a token for registration of additional persons.

The hospital has already registered with HMOs which automatically becomes their patient's choice. That is each hospital has its own chosen HMOs irrespective of the patients choices. Patients are not given the privilege to choose their HMO. In this system, there is little or no computerised system for the registration of patients in the hospital that would facilitate the processing of registration of patients for timely collection of NHIS permanent cards and also patients cannot enjoy the benefits of the scheme in another hospital where they are not registered as NHIS patients and this is so because of the lack of a centralized information system. This study designs a framework for easy, reliable, scalable, accessible and storage of patients' information for effective healthcare delivery.

\section{PROPOSED SYSTEM DESIGN AND ARCHITECTURE}

According to IBM, the web services architecture describes three roles: service provider, service requester

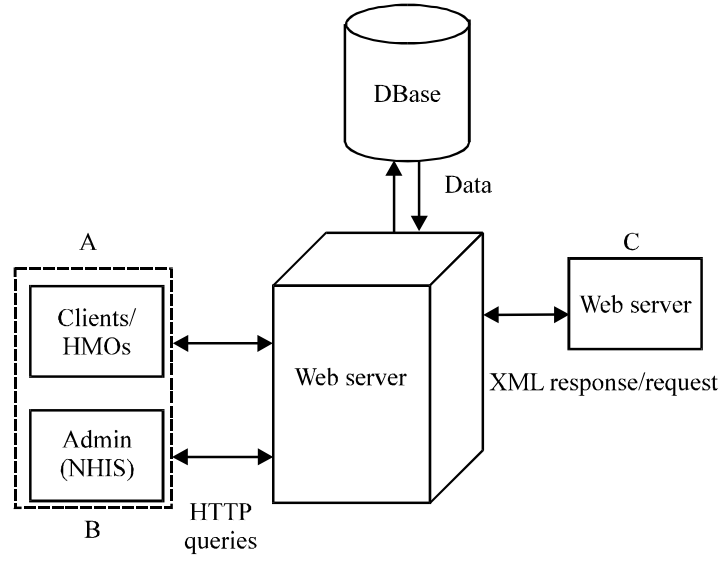

Fig. 3: Architecture of an Information Databank System for NHIS

and service broker and three basic operations: publish, find and bind. A network component can play any or all of these roles.

The proposed system involves the design of a centralized databank that could be used to help solve the already haphazard inter-related data repository of the NHIS visa vis services, funding, expertise and resources. The proposed system databank will consist of the scheme's information as regards the health practitioner's bio data, the pharmaceutical data, drug store, patients' bio data, treatment history and other services offered by the scheme.

The proposed system is a web based system that is to be regulated by the National Health Insurance Scheme being the body in charge of the daily activities of all the Health Maintenance Organizations (HMOs) registered in Nigeria. As described in Codd (1970) this proposed system uses both the human-centric and applicationcentric web approach as it allows the input of data into the system by the administrative body and also allowing the application to source for data itself using the web XML-services. In the web service is defined as a software system designed to support interoperable machine to machine interaction over a network (W3C, 2004).

Also, web services are self-contained, modular applications that can be described, published, located and invoked over a network, generally the world wide web (IBM Service Architecture Team, 2000; Moses, 2011).

The authentication and integrity of data is increased in the design. The blueprint design of the information databank is shown in Fig. 3. The architecture has both Parts A-C describing the human centric and the application centric web approaches. The human centric 
describes the activities of the humans to the web server whilst the application centric describes how the web server communicates with other web server for information requests/responds via $\mathrm{XML}$ web services.

\section{DESCRIPTION OF THE PROPOSED SYSTEM}

In Part A, researchers have the HMOs who are registered in the care scheme and have the privilege of sending and receiving information from the system. The request/response is via the HTTP query to the web server placed at the centre of the diagram. Part B describes the Administrators as the National Health Insurance Scheme who is the sole administrator of the scheme, it is charged with the responsibility of authentication of registered members and information sent into the databank for decision making processes. Part $\mathrm{C}$ uses the web XML request/response to communicate with other database system. It allows the various databases to communicate using the web XML request/response. That is an XML request is made to another web server (from NHIS server to $\mathrm{HMO}$ web server) and an XML response is received.

\section{RELATIONAL DATABASE DESIGN}

The proposed system's relational database consists of a various tables collections having unique names, attributes (columns) and rows (tuples) representing the relationships among sets of values. In Codd (1970) a Relational Database Model is represented as:

$$
\mathrm{R}_{0}=\left\{\mathrm{A}_{1}, \mathrm{~A}_{2}, \mathrm{~A}_{3}, \ldots, \mathrm{A}_{\mathrm{n}-1}, \mathrm{~A}_{\mathrm{n}}\right\}
$$

Where:

$\mathrm{R}=$ Represents a relation

$\mathrm{A}_{1}, \mathrm{~A}_{2}=$ Represents the attributes contained in the relation $\mathrm{R}$

From the definition given, the design of the proposed database relations for the NHIS is given below as:

Nhis \{nhis_id, provider_name, code, date_register, drug_generic_name\} Hospital \{hosp_id, hosp_name, hosp_contact, hosp_url, hosp_phone, hosp_email $\}$

Hmo \{hosp_no, hmo_id, hmo_name, hmo_plan, dob, date_register, capitation, drug_generic_name\}

Patient \{hosp_id, pat_id, pat_name, pat_age, pat_sex, ward_visited, remarks\}

Date_encounter_form \{id_no, name, Age, sex, diagnosis, drugs, minor_surgery, referral, lab_result, $x$ _ray, bed_days, date\}

Vital_signs \{pat_id, pat_temp, pat_respitation, pat_pulse, pat_height, pat_blood, pat_pressure, pat_weight $\}$

Drug \{hosp_id, generic_name, drug_list

Out_patient \{hosp_id, doctor_name, no_of_patient, diagnosis, treatment, signs\}

Documentation \{hosp_id, no_patient_in, no_refered, no_of_patients_wound_dressed injections_taken, medical examinations, attestation\}

The database table relationship is shown in Fig. 4.

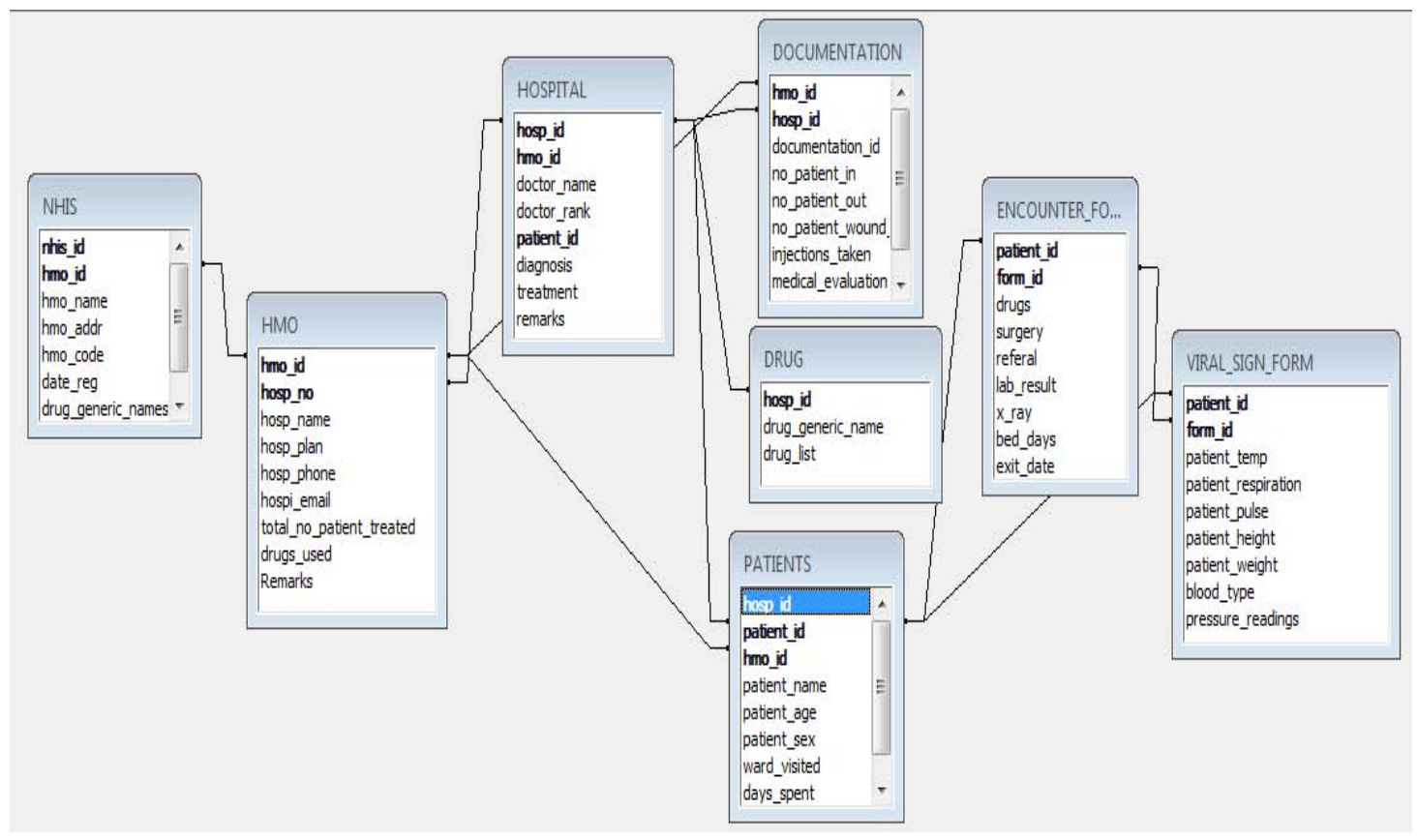

Fig. 4: Example of tables showing relationship between attribute keys 


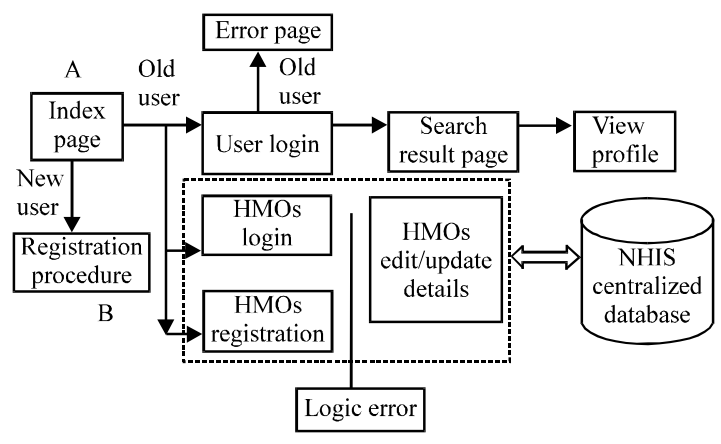

Fig. 5: Process flow diagram

\section{PROCESS SYSTEM DESIGN}

The process flow diagram is shown in Fig. 5 showing a quick view of the application usage from the users' perspective. The index page is the application start phase of the process flow with a users' login and registration module. The process flow diagram is divided into different modules which handle different activities. The Module A is for class of users that are registered and new users who wants to register for the first time. Module $\mathrm{B}$ comprises of class of HMOs, both the existing and new HMOs of the scheme. In Module B, all existing registered users of the system have their data stored in the centralise database with the NHIS which has the capacity of checking double registrations and duplications of data. When a user registers with his/her healthcare provider, the data is stored both with the provider and the HMO that handles the services of the provider, thereafter the data is sent to the centralised database. In Module $\mathrm{A}$, a user can update/edit records allowable. The user information update is required from time to time. As shown in the process flow diagram when patient's information is queried to facilitate care, results is provided immediately because of the centralised system operated. With this system, the number of registered patients can be determined accurately and healthcare can be easily monitored to ascertain the level of care in the country. The system design can run a stand alone Pentium III, $1.8 \mathrm{GHz}, 1 \mathrm{~GB}$ Ram computer system installed with Microsoft Windows Vista Operating System.

\section{APPLICATION AND DEPLOYMENET}

Like every other web application, the system can be deployed and hosted by common web hosting service providers like the Google, Yahoo, Alter Vista and hostmonster, etc. The service provider should be capable of hosting web pages designed with PHP/MySQL

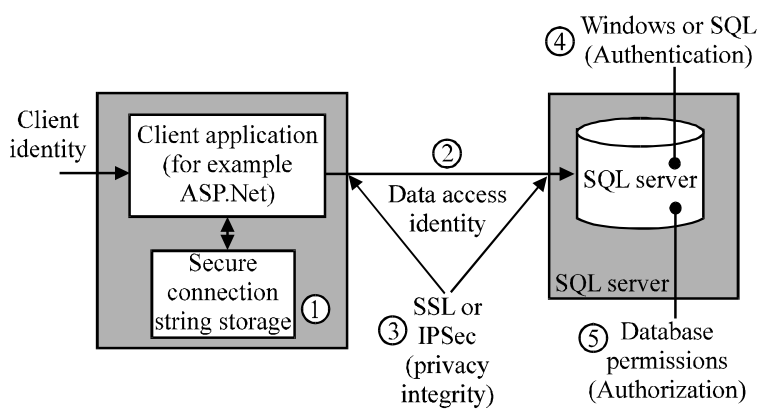

Fig. 6: Data access security key

features and accommodate large database spaces because of the large amount of anticipated volume of data to be used and analyzed by the system. Once the system is uploaded into the internet, it becomes readily accessible by all through the registered domain name. The system is relatively easy to use by anyone due to the user friendliness of the web pages.

\section{DATA SECURITY AND AUTHENTICATION}

Web system security is a very crucial issue when it comes to deploying medical records/data into the internet due to its sensitivity. With the use of a reliable and modern dedicated server deployed, unauthorized access and data theft can be minimized if not completely eradicated. Data authentication and security can further be strengthened by the use of professionals in handling the centralised database system. The application communication link between the application server and database must be able to guarantee message confidentiality and message integrity. A well defined web service structure of the application will prevent data replication and validate data from only authorised data sources. To further develop a secure data access strategy, the use of Windows authentication to the database, secured connection strings, storing credentials securely in a database, protecting against SQL injection attacks and using database roles should be applied as shown in Fig. 6.

\section{CONCLUSION}

The importance of having a centralized databank cannot be overemphasised due to the attendant benefit from the usage of present web technology. This study presents a technology for improving the activities of NHIS in patient information gathering through the webbased database system. If the system is fully deployed in the internet, it will present an enormous benefit for the 
scheme and the government for national planning vis a vis making informed and knowledgeable decisions about the health care delivery.

The proposed system was developed to work within the context of the present environment with existing limitations in implementing some aspects of the system. Some of the limitations are funding of the project, the non-availability of a web server and web services to handle the application-centric side of the project to retrieve information. This system was tested only on a stand alone system.

\section{RECOMMENDATIONS}

Further research may include creating data warehouse for such a large amount of data collected and applying data mining techniques/tools for knowledge discovery and effective knowledge-based decision making. Other research should also include the ability to capture, store, transform, summarise and analyze data.

\section{REFERENCES}

Adesina, D., 2009. The national health insurance scheme. http://nigeriandoctor.com/print.php?news.850.

Chiemeke. S.C., F. Egbokhare and G. Ekuobase, 2004. Data Processing and Management Information System. 2nd Edn., Ardik Publishers, Benin, Africa.

Codd, E.F., 1970. A relational model of data for large shared data banks. Commun. ACM, 13: 377-387.
Duckett. S.T., 2004. The Australian Health Care System. 2nd Edn., Oxford University, USA.

IBM Service Architecture Team, 2000. Web services architecture overview. http://www.ibm.com/developerworks/webservices/library/w-ovr/.

Kaur, H. and S.K. Wasan, 2006. Empirical study on applications of data mining techniques in healthcare. J. Comput. Sci., 2: 194-200.

Moses, J., 2011. Nigeria: Challenges of taking NHIS to private sector. http://allafrica.com/stories/2011101600 12.html.

Obembe. O.M. and O.S. Ogundele, 2009. An information databank for the health care industry in Nigeria. Int. J. Comput. ICT Res., 3: 47-57.

Piattini, M. and O. Diaz, 2000. Advanced Database Technology and Design. Artech House, London, UK, ISBN: 9780890063958, Pages: 535.

Van Bemmel, J.H., 1997. Handbook of Medical Informatics. Bohn Stafleu Van Loghum Publishing, Netherlands, ISBN: 9783540633518 , Pages: 621.

W3C, 2004. Web services architecture W3C working group note. http://www.w3.org/TR/ws-arch/\#stakeholder_using.

WHO, 2000. Health Systems: Improving Performance. World Health Organization, Geneva, Switzerland.

Wiederhold, G., E. Shortliffe, L. Fagan and L. Perreault, 2001. Medical Informatics: Computer Applications in Health Care and Biomedicine. 2nd Edn., Springer, New York, ISBN-10: 0387984720, pp: 854. 